\title{
Current and Emerging Therapeutics for Cutaneous T-Cell Lymphoma: Histone Deacetylase Inhibitors
}

\author{
Annabelle L. Rodd, ${ }^{1,2}$ Katherine Ververis, ${ }^{1,2}$ and Tom C. Karagiannis ${ }^{1,2}$ \\ ${ }^{1}$ Epigenomic Medicine, Baker IDI Heart and Diabetes Institute, The Alfred Medical Research and Education Precinct, \\ Melbourne, VIC 3004, Australia \\ ${ }^{2}$ Department of Pathology, The University of Melbourne, Parkville, VIC 3010, Australia
}

Correspondence should be addressed to Tom C. Karagiannis, tom.karagiannis@bakeridi.edu.au

Received 30 May 2012; Accepted 23 June 2012

Academic Editor: Vincent Ribrag

Copyright (C) 2012 Annabelle L. Rodd et al. This is an open access article distributed under the Creative Commons Attribution License, which permits unrestricted use, distribution, and reproduction in any medium, provided the original work is properly cited.

Cutaneous T-cell lymphoma is a term that encompasses a spectrum of non-Hodgkin's T-cell lymphomas with primary manifestations in the skin. It describes a heterogeneous group of neoplasms that are characterised by an accumulation of malignant $\mathrm{T}$ cells of the CD4 phenotype that have the propensity to home and accumulate in the skin, lymph nodes, and peripheral blood. The two most common variants of cutaneous T-cell lymphoma include mycosis fungoides and the leukemic variant, the Sézary syndrome. While numerous treatments are available for cutaneous T-cell lymphoma and have shown to have success in those with patch and plaque lesions, for those patients with tumour stage or lymph node involvement there is a significant decline in response. The relatively new therapeutic option with the use of histone deacetylase inhibitors is being advanced in the hope of decreasing morbidity and mortality associated with the disease. Histone deacetylase inhibitors have been shown to induce changes in gene expression, affecting cell cycle regulation, differentiation, and apoptosis. The aim of this paper is to discuss CTCL in the context of advances in CTCL treatment, specifically with HDAC inhibitors.

\section{Cutaneous T-Cell Lymphoma}

Cutaneous T-cell lymphomas (CTCLs) are a heterogenous group of extranodal non-Hodgkin's T-cell lymphomas derived from $\mathrm{T}$ lymphocytes that infiltrate the skin $[1,2]$. CTCL is characterised by an accumulation of malignant $\mathrm{T}$ cells of the CD4 phenotype that target and persist in the skin, yet have the propensity to home and accumulate in the lymph nodes and peripheral blood as the disease progresses [2-6]. The term CTCL was coined in 1974 by Edelson $[4,7]$ to describe the major classifications of CTCL, including mycosis fungoides (MF) and the leukemic variant the Sézary syndrome (SS). Although a rare condition, in its advanced or transformed stages it is a debilitating and devastating disease, differing dramatically in its clinical and histopathologic presentations and subsequent therapeutic considerations [8]. While a number of therapies are available for the treatment of this disease, generally patients develop progressive disease after becoming treatment intolerant or refractory to multiple therapies.

The annual incidence of CTCL is approximately 0.5 per 100,000 , having a higher prevalence among men than women (male-to-female ratio of $1.6: 1-2.0: 1$ ) and typically seen in adults with a median age of 55-60 years at diagnosis $[9,10]$. The exact number of cases is difficult to determine due to the lack of a definitive diagnoses at early stages. This is in part due to the presence of multiple clinical presentations. Indeed, at the onset of the disease, both symptoms and skin biopsy samples mimic benign skin conditions such as eczema, psoriasis, chronic contact dermatitis, and atopic dermatitis [11]. For these reasons it takes on average 6 years from the onset of disease until the diagnosis of CTCL is confirmed [12]. In recent years, however, the number of diagnoses has been on the rise, where the annual incidence in the United States has risen from 2.8 per million, 1973-1977, to 9.6 per million 1998-2002 [13]. This is most likely a result 
of advances in detection methods of the disease at early stages $[9,14]$. The introduction of more sensitive biological tools such as immunotyping and gene rearrangement studies has contributed towards higher accuracy of diagnosis $[14,15]$.

CTCL has a diverse pathology and clinical course; MF presents generally as an indolent disease with slow progression where it will evolve from patches to infiltrated plaques, later developing into tumours. In a small population of cases the erythrodermic stage will arise, at which point the disease is known as SS. Accurate staging of the disease is essential, as the choice of therapy is highly dependent upon the clinical stage of the disease [18-20]. In 1975 the disease was first categorised into stages based on a tumournode-metastasis (TMN) system by the North American Mycosis Fungoides Cooperative Study Group (Table 1). Consequently, the classification has been updated and modified by the cutaneous T-cell lymphoma workshop $[1,21]$ to the system used today (Table 2) [12, 15-17]. The extent of pathogenesis and expected outcome are dependent on various prognostic factors such as the extent and type of skin involvement, presence of extracutaneous disease, and blood involvement. There is a positive correlation between survival rate and disease progression. As an example, at the onset of disease, life expectancy matches that of equivalent age healthy controls, whilst at the final stages the life expectancy reduces to between 3.2 and 9.9 years.

The annual prevalence of MF is 0.41 per 100,000; however the rate of incidence is increasing [10]. MF, first described by Alibert in 1806 [22], is characterised by the presence of malignant T lymphocytes in the skin. While the course of MF is unpredictable, patients generally present with pink or erythematous scaly patches and plaques that most commonly are seen on sun-protected regions of the skin, including the proximal extremities, trunk, and buttockswith varying degrees of scaling and pruritus [5, 11]. MF is a low-grade lymphoma where the median survival for patients with limited patch lesions is the same as an agematched population, and prognosis is good. During patch stage, a biopsy will generally indicate an atypical lymphocytic infiltrate. Alternatively during late patch or plaque stage, the lymphocytic infiltrate is observed to have migrated to the superficial dermis, where individual lymphocytes are present among epidermal keratinocytes. The neoplastic cells, when encountering the ligand E-selectin on endothelial cells, eventually arrive at the skin via expression of the cutaneous lymphocyte-associated (CLA) marker [23]. While CLA is a known marker for skin-homing $\mathrm{T}$ cells, recent reports have stated that CLA's ability to mediate leukocyte homing to skin depends on specific chemokine receptor-ligand interactions [24]. Specifically the chemokine receptor CCR4 has been implicated in the process due to the increased presence of CLA+ CCR4 $+\mathrm{T}$ cells in the circulation of CTCL patients with peripheral blood involvement $[23,25]$.

Conversely, in less than $5 \%$ of all cases of CTCL, the disease can progress to tumour stage lesions, where malignant $\mathrm{T}$ cells form intradermal and ulcerating tumours that spread to the lymph nodes and internal organs [26]. Known as the leukemic variant of CTCL, the condition SS can result as a progression of MF to a more advanced form
TABLE 1: TMN staging system. Clinical staging system for cutaneous T-cell lymphoma. This classification is designed to select the appropriate treatment at the variant stages of the lymphoma [1517].

\begin{tabular}{|c|c|}
\hline $\mathrm{T} 1$ & Plaques and/or patches $<10 \%$ body surface area \\
\hline $\mathrm{T} 2$ & Plaques and/or patches $\geq 10 \%$ body surface area \\
\hline T3 & $\geq 1$ cutaneous tumours \\
\hline $\mathrm{T} 4$ & Erythroderma \\
\hline NN0 & No lymph nodes involved \\
\hline N1 & $\begin{array}{l}\text { Lymph nodes enlarged without histological } \\
\text { involvement }\end{array}$ \\
\hline N2 & $\begin{array}{l}\text { Nonpalpable lymph nodes with histological } \\
\text { involvement }\end{array}$ \\
\hline N3 & Enlarged lymph nodes with histological involvement \\
\hline M0 & No visceral disease \\
\hline M1 & Visceral disease \\
\hline B0 & $\begin{array}{l}\text { No haematological involvement-no atypical (Sézary) } \\
\text { cells, }<5 \%\end{array}$ \\
\hline B1 & $\begin{array}{l}\text { Atypical (Sézary) cells circulating, } \geq 5 \% \text { of total } \\
\text { peripheral lymphocytes }\end{array}$ \\
\hline
\end{tabular}

TABLe 2: Bunn and Lambert system. This stage classification uses the TMN staging system to subclassify the clinical disease progression.

\begin{tabular}{lc}
\hline Stage IA & T1 N0 M0 \\
Stage IIB & T2 N0 M0 \\
Stage IIA & T1/2 N1 M0 \\
Stage IIB & T3 N0/1 M0 \\
Stage III & T4 N0/1 M0 \\
Stage IVA & T1-4 N2/3 M0 \\
Stage IVB & T1-4 N0-3 M1 \\
\hline
\end{tabular}

or may arise de novo [3, 11]. First classified in 1938 by the Sézary, SS is typically identified as having the triad of measurable blood involvement by malignant lymphocytes with hyperconvoluted, cerebriform nuclei known as the Sézary cells, the presence of diffuse erythema ( $>80 \%$ body surface area involved with patches/plaques), and finally generalised lymphadenopathy [27]. In these advanced stages, prognosis is poor and the median survival rate is two to four years $[28,29]$.

\section{Current Therapy Options for CTCL}

A myriad of treatments are available for CTCL, yet therapy is predominantly palliative and highly dependent upon the stage at diagnosis. Treatment is broadly divided into two categories - skin-directed and systemic therapies. Skindirected treatments are the first-line agents during the early stages of the disease (IA to IIA) when less than $20 \%$ of the body surface area is affected $[11,30]$. While this has shown to be effective, as the disease progresses and patients develop extensive or refractory disease, systemic therapy becomes essential. During these advanced stages ( $\geq$ IIB), a wide scope of treatments exists. One approach includes 
topical chemotherapeutic agents such as mechlorethaminecommonly known as nitrogen mustard - and carmustine. Chemotherapy has proved to be successful in patients with early-stage disease; however in those with more advanced stages and greater skin involvement, responses are not maintained and complete remission is infrequent [31].

An additional treatment often introduced at more advanced stages is corticosteroids. Studies have shown that topical corticosteroids, especially Class I, are useful for patchstage MF [32]. However, while clinical responses may be achieved at later stages, they are generally not maintained and disease relapses [33]. In the case of resistance or intolerance to topical therapies mentioned above, the novel topical retinoid, bexarotene, also known as Targretin, is employed. Recently being approved by the FDA for treatment of stage I MF patients [34], bexarotene is a retinoid that binds the retinoid $\mathrm{X}$ receptor, causing activation and in turn promoting apoptosis and inhibition of cell proliferation [30]. Reports have shown response rates of up to $63 \%$, and in the case of stage IA-IIA disease, complete response rates in $21 \%$ of individuals [34]. Finally, CTCL is radiosensitive rendering both low-dose superficial orthovoltage radiotherapy and whole-body total skin electron beam (TSEB) therapy viable options of treatment for advanced stages of the disease. TSEB delivers uniform, limited-depth electrons to the entire skin surface area $[12,35]$. While studies have shown this technique to have high complete response rates, up to $96 \%$ in stages IB, IIA, and IIB, once again considerably high relapse rates are concerning. Further, due to the high doses required, the treatment is accompanied by a wide scope of adverse effects such as temporary alopecia and skin malignancies [30]. In numerous cases lesions occur in nonexposed areas, and so the use of ultraviolet (UV) radiation is necessary. Both $\mathrm{UV}_{\mathrm{B}}$ irradiation and a photosensitising psoralen in combination with $\mathrm{UV}_{\mathrm{A}}$ irradiation (PUVA) have been implicated for the treatment of CTCL.

While numerous treatment modalities are already in use for CTCL, most remain palliative, and for those with advanced stages of disease, prolonged remissions or cures are rare. In this regard, novel treatments are necessary in order to combat CTCL and render lower levels of morbidity and mortality and further achieve longer durations of response. Over the past few years, there has been an explosion into novel therapeutics for the treatment of CTCL, one new approach being HDAC inhibitors (HDACIs). HDACIs have recently evoked significant amounts of attention emerging as a promising class of antineoplastic agents that promote gene expression, including those that regulate cell differentiation and apoptosis [36] as well as changes to the structural integrity of chromatin [37].

\section{Epigenetic Mechanisms}

Aberrant HDAC activity and mutations of HDAC enzymes have been observed in a number of malignancies. Aside from gene regulation, HDACs are either directly or indirectly involved in modulating numerous cellular pathways including proliferation, apoptosis, migration, and differentiation
[37-39]. This provides the rationale for the clinical potential of HDACI in cancer therapy, whereby inhibition of HDACs may prevent reexpression of proteins that promote apoptosis and cell differentiation, while simultaneously inhibiting cell cycle and cell division [40]. Hence a number of these compounds are currently being developed as anti-tumour agents that both suppress growth and induce apoptosis of hyperproliferating cancer cells [41]. Class I, II, and IV HDACs are evolutionarily related zinc-dependent deacetylases that can be inhibited by broad-spectrum HDACI, such as suberoylanilide hydroxamic acid (SAHA, vorinostat). Various classes of HDACIs have been used either clinically or experimentally for the management of CTCL. As of 2010, over 80 clinical trials were underway, encompassing more than 15 different HDACIs for the treatment of both solid and haematological malignancies, either alone or in combination with other therapeutic modalities [42].

\section{Histone Acetylation}

In eukaryotes chromatin is organised by packaging it into higher-order structures known as nucleosomes. These are repeating units of 146 base pairs (bp) of DNA wrapped around the core histone octamer, composed of two copies of each of H2A, H2B, H3, and $\mathrm{H} 4$ [37, 43]. Chromatin undergoes dynamic remodelling to facilitate DNA metabolic processes including transcription, replication, and repair [44]. Remodelling of chromatin via posttranslational modifications of the $\mathrm{N}$-amino tails of the histones has numerous effects on DNA metabolism including the alteration of gene transcription. The posttranslational modifications of these proteins are characterised by acetylation, methylation, phosphorylation, ubiquitination, and sumoylation and are collectively termed the "histone code" [45]. These posttranslational modifications cause changes in transcription and other DNA metabolic processes, while the DNA sequence remains the same-referred to as epigenetic changes.

Histones have an amino-terminal tail rich in lysine residues that are the sites for the majority of posttranslational modifications. A relatively well-characterized epigenetic modification of these histone tails is acetylation [46]. Histones can be acetylated and deacetylated at the $\varepsilon$-amino groups of lysine residues, which are located in the amino-terminal tails [47]. Their acetylation status is dependent on the opposing actions of two classes of enzymes, histone acetyl-transferases (HATs), and histone deacetylases (HDACs) [48]. Acetylation is catalysed by HATs, where acetyl groups are transferred from acetyl-CoA to certain lysines at the amino terminal tail, causing a more open, transcriptionally active chromatin conformation $[49,50]$. Conversely HDACs remodel chromatin by changing nucleosomal packaging of DNA. They are primarily involved in the repression of gene transcription by compacting the chromatin structure through the removal of the charge-neutralising acetyl groups (deacetylation) from the lysine tails of histones $\mathrm{H} 3$ and $\mathrm{H} 4$, subsequently inhibiting transcription [51]. Overall, it is proposed that acetylation levels regulate gene transcription by controlling the accessibility of transcription factors to 


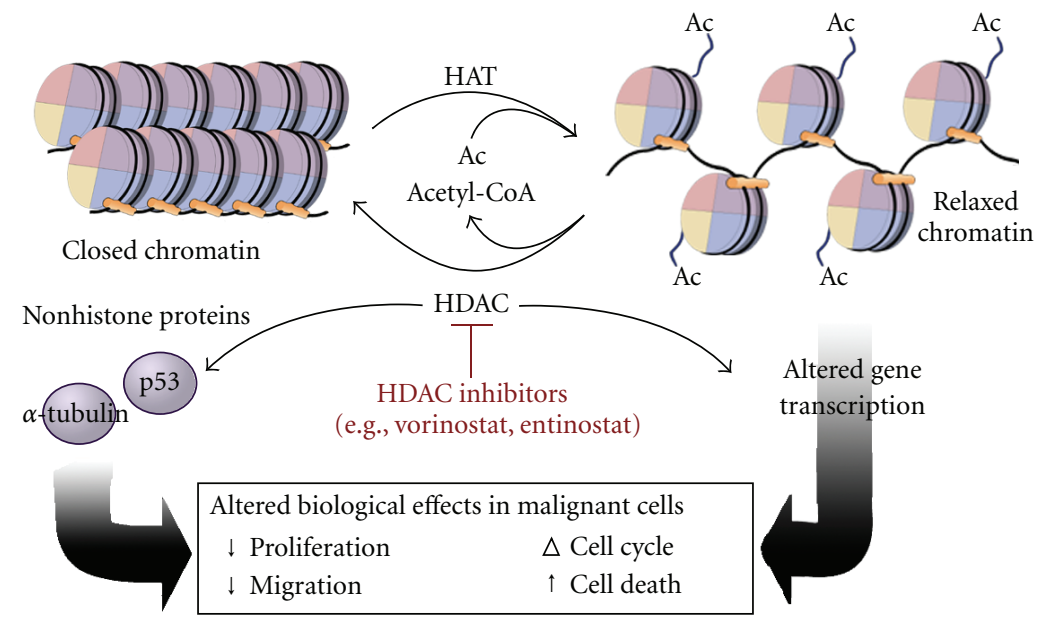

FIGURE 1: Histone acetylation is regulated by the addition of acetyl-CoA via the opposing actions of histone acetyltransferases (HATs) and histone deacetylases (HDACs) in lysine resides on core histones. This addition of the acetyl group results in a more open, transcriptionally permissive chromatin conformation. Removal of acetyl groups by HDACs leads to a condensed, transcriptionally repressive chromatin conformation. HDACIs inhibit HDAC activity, subsequently altering gene transcription and remodelling chromatin by targeting a number of nonhistone proteins.

DNA [44]. Therefore inhibition of HDAC enzymes results in disruption of the balance between the deacetylation activity of HDACs and the acetylation activity of HATs, resulting in hyperacetylation of core histones [52] (Figure 1).

\section{Histone Deacetylases}

HDAC enzymes have been divided into 4 classes based on their sequence, biochemical, and structural similarities to yeast proteins $[53,54]$ (Figure 2). Class I (HDAC1, 2, 3, and 8) HDACs are expressed ubiquitously in tissue and consist mainly of a deacetylase domain, related to yeast reduced potassium dependency-3 (Rpd-3). They are found primarily in the nucleus [55] and have important roles in regulating gene transcription, cell survival, and proliferation [56]. Class II HDACs are highly expressed in muscle, brain, and T cells and have an extended $\mathrm{N}$-terminus that serves as a target for protein-protein interactions and for posttranslational modifications. This class is divided into Class IIa, which encompasses HDAC4, 5, 7, and 9, and is related to yeast histone deacetylase-1 (Hda1), and Class IIb, which includes HDAC6 and 10, both of which have two catalytic sites. Class III (SIRT1, 2, 3, 4, 5, 6, and 7) is related to the yeast HDAC silent information regulator 2 and uses nicotinamide adenine dinucleotide as a cosubstrate. Finally, Class IV (HDAC11) is considered to be structurally diverse enough from the other $\mathrm{Zn}^{+}$-dependent HDACs to be classified as a separate class but has conserved residues which are common in both Class I and Class II.

\section{HDAC Inhibitors}

HDACIs have been separated into certain classes depending on their functional group, which confers their specificity for interaction with HDACs [57]. Groups include short-chain fatty acids, hydroxamates, benzamides, cyclic tetrapeptides, and electrophilic ketones $[58,59]$. A number of HDACIs have shown to inhibit tumour growth both in vitro and in vivo [60]. As such, in recent years HDACIs have undergone rapid clinical development for the treatment of CTCL [61] (Table 3).

\section{Vorinostat}

A prominent HDACI is the oral pan-spectrum inhibitor, suberoylanilide hydroxamic acid (SAHA, vorinostat, Zolinza). In 2006, vorinostat became the first drug to be approved for clinical use by the US Food and Drug Administration (FDA) for the treatment of progressive, persistent, or recurrent CTCL after which two systemic therapies have failed $[42,62]$. The study which led to this approval was a single-arm open-label Phase II trial. This study enrolled 74 patients with stage IB or higher, including $82 \%$ with $\geq$ IIB. The overall response rate was $29.7 \%$. Oral vorinostat was administered at $400 \mathrm{mg}$ daily. The median time to response was 2 months, and median duration of response was not reached but was estimated to be greater than 6.1 months [63]. A further Phase II trial involving 33 patients with advanced or refractory CTCL had a $24 \%$ overall response rate with a median response time of 3 months and a median duration of response for 3.7 months [64]. Side effects of this drug include fatigue, gastrointestinal effects, thrombocytopenia, and dehydration [65].

\section{Depsipeptide}

The cyclic tetrapeptide depsipeptide (Romidepsin, FK228) has also been approved for the treatment of relapsed/ refractory CTCL after patients have received at least one 


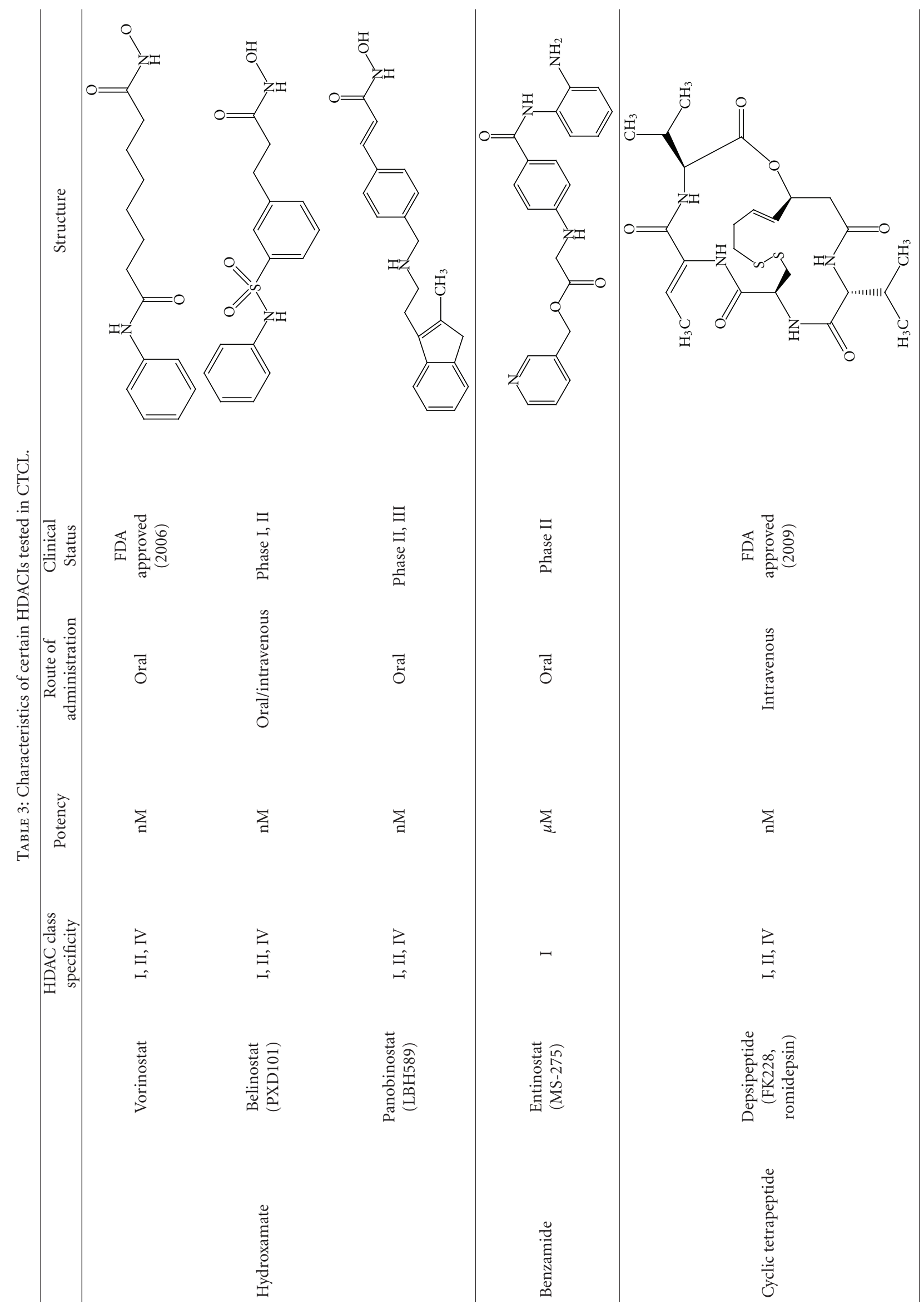



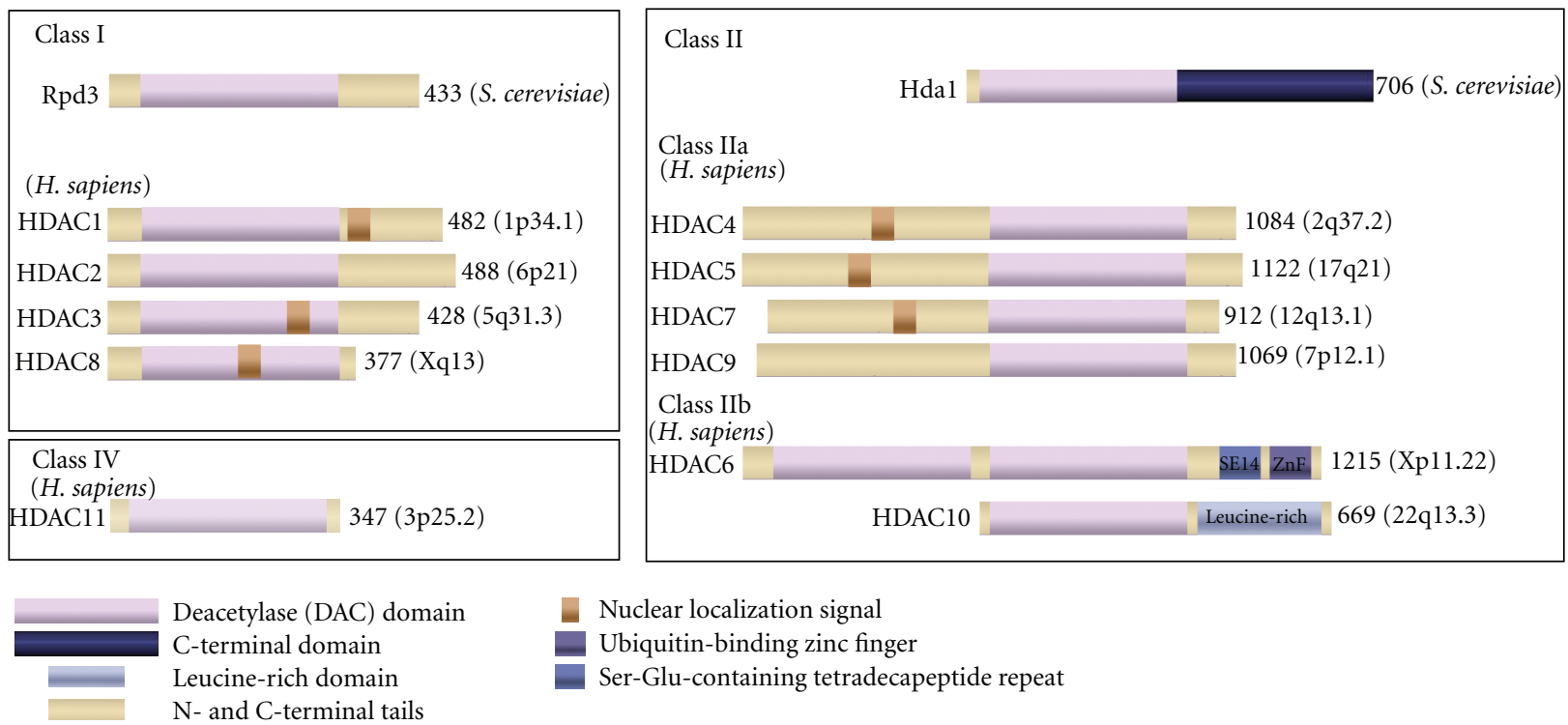

FIGURE 2: Schematic representation of the classical Class I, II, and IV mammalian HDACs. HDAC enzymes have been separated into 4 classes based on their homology to yeast proteins. Class I enzymes are structurally similar to the yeast, reduced potassium dependency-3 (Rpd3) and consisting of HDAC1, 2, 3, and 8. Class II HDACs are related to the yeast, histone deacetylase-1 (Hda 1). This class is subdivided into two classes-Class IIa (HDAC4, 5, 7, 9) and Class IIb (HDAC6, 10). The HDACs have a conserved deacetylase (DAC) domain. The number of amino acid residues of the longest isoform of each HDAC is shown on the right.

prior systemic therapy $[59,66,67]$. Isolated as a secondary metabolite from the naturally occurring soil bacterium Chromobacterium violaceum, depsipeptide achieved FDA approval in 2009 following two Phase II trials were undertaken including 167 patients with relapsed, refractory, or advanced CTCL [68]. Depsipeptide was administered intravenously at $14 \mathrm{mg} / \mathrm{m}^{2}$ on days 1,8 , and 15 of a 28 -day cycle. In both trials, the overall response rate was $34 \%$, while the complete response rate was $6 \%$. The median time to response was 2 months, and the median duration of response was greater than 12 months [64, 69]. Depsipeptide, being a bicyclic peptide, is a Class I-specific HDACI [70] and has shown to induce cell differentiation, cell cycle arrest in the $G_{1}$ and $G_{2} / M$ phases, and apoptosis in malignant cell lines. This HDACI is generally well tolerated, the most common adverse effects including fatigue, nausea, vomiting, and transient thrombocytopenia and neutropenia [71]. Depsipeptide, together with vorinostat has demonstrated to be clinically efficacious and has so prompted the investigation into other HDACIs as potential anticancer compounds in the treatment of CTCL.

\section{Entinostat}

The synthetic benzamide derivative entinostat (SNDX-275, formerly MS-275), currently in Phase II trials [68], has shown to have selective Class I HDAC inhibitory activity and has further demonstrated antiproliferative properties in a number of tumour models [72]. Studies have highlighted several mechanisms of action for this HDACI including induction of apoptosis via activation of the intrinsic caspase pathway and downregulation of the inhibitor of apoptosis protein, XIAP, as well as regulation of certain cytokines and chemokines [73]. Patients suffering CTCL have an impaired Th1 response, where there is a skewed immune system towards a Th2 response. This results due to the increased production of certain cytokines, namely, IL-3, Il4, and Il-10, by the malignant $\mathrm{T}$ cells that subsequently lead to inhibition of Th1 cytokines [74-77]. Specifically, pharmacodynamic analysis reveals that following treatment with entinostat, there is increased production of IL-12, a cytokine that is important for Th1 cell differentiation. Additionally, it also decreases expression of IL-13 causing inhibition of the Th2 arm of the immune response [73].

\section{Belinostat}

looseness=1An additional HDACI currently in late-stage clinical development for the treatment of CTCL is belinostat (PXD101). This novel hydroxamic acid HDACI has shown to be well tolerated and has demonstrated promising results in combination with a number of traditional chemotherapeutic compounds [78]. Preclinical experiments highlighted the ability of belinostat to inhibit cell proliferation and angiogenesis, while inducing differentiation and apoptosis in malignant cells [79]. Subsequently this compound has been tested in multiple Phase I $[80,81]$ and Phase II [82] clinical trials in haematological neoplasms and solid tumours, including CTCL. Belinostat is the only HDACI in clinical development that has multiple potential routes of administration-including oral and intravenous. 


\section{Panobinostat}

Also belonging to the hydroxamic-type HDACI is panobinostat (LBH589). Panobinostat, like vorinostat and belinostat, is a pan-HDACI having demonstrated potent inhibitory activity at low nanomolar concentrations against Class I, II, and IV HDAC enzymes [83]. This HDACI, currently in Phase II clinical trials, remarkably has shown to be at least tenfold more potent in comparison to vorinostat [83]. This compound has further shown to inhibit proliferation and induce cytotoxicity in a number of malignant cell lines, while having minimal toxicity in normal cell lines [84]. The most common drug-related side effects were thrombocytopenia, anemia, and neutropenia [85]. Specifically studies demonstrated its antineoplastic activity in numerous haematological malignancies, particularly CTCL [61]. These positive clinical responses in CTCL can possibly be attributed to changes in gene expression leading to antiangiogenic, immune modulation, and alteration of apoptotic properties.

\section{Conclusions and Future Directions}

Numerous treatments are currently available for CTCL, and while partial or complete remission can be achieved, subsequent relapses are common and curative therapy remains elusive. As such there is an intense research effort aimed at developing new therapies. HDACIs have demonstrated to be potent antiproliferative agents and further have shown in vitro and in vivo cytotoxicity against CTCL [86]. Two HDACIs, namely, vorinostat and romidepsin, have already achieved FDA approval for the treatment of cutaneous manifestations in patients with CTCL who have progressive, persistent, or recurrent disease following the failure of two systemic therapies. The clinical success of these two compounds, which have demonstrated to induce disease regression in CTCL, has prompted the investigation into a multitude of additional HDACIs for the treatment of this disease. A number of promising results have been obtained from studies involving these novel antineoplastic agents, and so the future of HDAC-inhibitor-based therapy, especially in the context of enhancing efficacy, is exciting. Further, it alludes to possible combination therapies with therapeutic agents already in practice, a treatment option that has previously shown to achieve additive and even synergistic activity.

\section{Acknowledgments}

The support of the Australian Institute of Nuclear Science and Engineering (AINSE) is acknowledged. T. C. Karagiannis was the recipient of the AINSE awards. A. L. Rodd is the recipient of the Baker IDI Bright Spark Top-Up and Australian and AINSE post-graduate awards. The Epigenomic Medicine Laboratory is supported by McCord Research and supported in part by the Victorian Government's Operational Infrastructure Support Program. A. L. Rodd, K. Ververis and T. C. Karagiannis declare that they have no direct financial relation with the commercial identities mentioned in this paper that might lead to a conflict of interests.

\section{References}

[1] R. Willemze, E. S. Jaffe, G. Burg et al., "WHO-EORTC classification for cutaneous lymphomas," Blood, vol. 105, no. 10, pp. 3768-3785, 2005.

[2] P. Ponte, V. Serrão, and M. Apetato, "Efficacy of narrowband UVB vs. PUVA in patients with early-stage mycosis fungoides," Journal of the European Academy of Dermatology and Venereology, vol. 24, no. 6, pp. 716-721, 2010.

[3] T. Krejsgaard, K. Kopp, E. Ralfkiaer et al., "A novel xenograft model of cutaneous T-cell lymphoma," Experimental Dermatology, vol. 19, no. 12, pp. 1096-1102, 2010.

[4] R. L. Edelson, "Cutaneous T cell lymphoma: mycosis fungoides, Sezary syndrome, and other variants," Journal of the American Academy of Dermatology, vol. 2, no. 2, pp. 89-106, 1980.

[5] D. V. Kazakov, G. Burg, and W. Kempf, "Clinicopathological spectrum of mycosis fungoides," Journal of the European Academy of Dermatology and Venereology, vol. 18, no. 4, pp. 397-415, 2004.

[6] M. Girardi, P. W. Heald, and L. D. Wilson, "The pathogenesis of mycosis fungoides," New England Journal of Medicine, vol. 350, no. 19, pp. 1978-1988, 2004.

[7] R. L. Edelson, "Outsmarting cutaneous T-cell lymphoma cells by decoding the language they speak: focusing past and present insights on future prospects," Clinical Lymphoma, Myeloma and Leukemia, vol. 10, no. 2, pp. S59-S62, 2010.

[8] F. Glass, K. L. Keller, J. L. Messina et al., "The diagnosis and treatment of cutaneous T-cell lymphoma are challenging due the many clnical and histopathologic presentations of the disease," Cancer Control, vol. 5, no. 1, 1998.

[9] R. Willemze, "Cutaneous T-cell lymphoma: epidemiology, etiology, and classification," Leukemia and Lymphoma, vol. 44, supplement 3, pp. S49-S54, 2003.

[10] P. T. Bradford, S. S. Devesa, W. F. Anderson, and J. R. Toro, "Cutaneous lymphoma incidence patterns in the United States: a population-based study of 3884 cases," Blood, vol. 113, no. 21, pp. 5064-5073, 2009.

[11] M. Girardi and R. L. Edelson, "Cutaneous T-cell lymphoma: pathogenesis and treatment," Oncology, vol. 14, no. 7, pp. 1061-1070, 2000.

[12] E. Diamandidou, P. R. Cohen, and R. Kurzrock, "Mycosis fungoides and Sezary syndrome," Blood, vol. 88, no. 7, pp. 2385-2409, 1996.

[13] A. Markova and M. A. Weinstock, "Trends in cutaneous lymphoma epidemiology," Clinical Lymphoma, Myeloma and Leukemia, vol. 10, no. 2, pp. S63-S66, 2010.

[14] B. D. Smith and L. D. Wilson, "Management of mycosis fungoides: Part 1. Diagnosis, staging, and prognosis," Oncology, vol. 17, no. 9, pp. 1281-1288, 2003.

[15] R. S. Siegel, T. Pandolfino, J. Guitart, S. Rosen, and T. M. Kuzel, "Primary cutaneous T-cell lymphoma: review and current concepts," Journal of Clinical Oncology, vol. 18, no. 15, pp. 2908-2925, 2000.

[16] M. Girardi, P. W. Heald, and L. D. Wilson, "The pathogenesis of mycosis fungoides," New England Journal of Medicine, vol. 350, no. 19, pp. 1978-1988, 2004.

[17] P. A. Bunn and S. I. Lamberg, "Report of the committee on staging and classification of cutaneous T-cell lymphomas," Cancer Treatment Reports, vol. 63, no. 4, pp. 725-728, 1979. 
[18] F. Trautinger, R. Knobler, R. Willemze et al., "EORTC consensus recommendations for the treatment of mycosis fungoides/Sézary syndrome," European Journal of Cancer, vol. 42, no. 8, pp. 1014-1030, 2006.

[19] R. Dummer and M. Dreyling, "Primary cutaneous lymphoma: ESMO clinical recommendations for diagnosis, treatment and follow-up," Annals of Oncology, vol. 19, supplement 2, pp. ii72-ii76, 2008.

[20] S. M. Horwitz, E. A. Olsen, M. Duvic, P. Porcu, and Y. H. Kim, "Review of the treatment of mycosis fungoides and Sézary syndrome: a stage-based approach," Journal of the National Comprehensive Cancer Network, vol. 6, no. 4, pp. 436-442, 2008.

[21] M. Girardi and R. L. Edelson, "Cutaneous T-cell lymphoma: pathogenesis and treatment," Oncology, vol. 14, no. 7, pp. 1061-1070, 2000.

[22] J. Alibert, Description des Maladies de la Peau: Observees a L'HospitaL St. Louis, Barrois L’Aine et Fils, Paris, France, 1806.

[23] K. Ferenczi, R. C. Fuhlbrigge, J. L. Pinkus, G. S. Pinkus, and T. S. Kupper, "Increased CCR4 expression in cutaneous T cell lymphoma," Journal of Investigative Dermatology, vol. 119, no. 6, pp. 1405-1410, 2002.

[24] J. J. Campbell, G. Haraldsen, J. Pan et al., "The chemokine receptor CCR4 in vascular recognition by cutaneous but not intestinal memory T cells," Nature, vol. 400, no. 6746, pp. 776780, 1999.

[25] C. Vestergaard, K. Bang, B. Gesser, H. Yoneyama, K. Matsushima, and C. G. Larsen, "A $\mathrm{Th}_{2}$ chemokine, TARC, produced by keratinocytes may recruit $\mathrm{CLA}^{+} \mathrm{CCR} 4^{+}$lymphocytes into lesional atopic dermatitis skin," Journal of Investigative Dermatology, vol. 115, no. 4, pp. 640-646, 2000.

[26] B. Poligone, "Romidepsin: evidence for its potential use to manage previously treated cutaneous T cell lymphoma," Core Evidence, vol. 6, pp. 1-12, 2011.

[27] V. Kumar, N. Fausto, and A. Abbas, Robbins and Cotran Pathologic Basis of Disease, Elsevier Saunders, 9th edition, 2010.

[28] T. M. Kuzel, H. H. Roenigk, and S. T. Rosen, "Mycosis fungoides and the Sezary syndrome: a review of pathogenesis, diagnosis, and therapy," Journal of Clinical Oncology, vol. 9, no. 7, pp. 1298-1313, 1991.

[29] R. Van Doorn, C. W. Van Haselen, P. C. Van Voorst Vader et al., "Mycosis fungoides: disease evolution and prognosis of 309 Dutch patients," Archives of Dermatology, vol. 136, no. 4, pp. 504-510, 2000.

[30] S. J. Whittaker, J. R. Marsden, M. Spittle, and R. Russell Jones, "Joint British Association of Dermatologists and U.K. Cutaneous Lymphoma Group guidelines for the management of primary cutaneous T-cell lymphomas," British Journal of Dermatology, vol. 149, no. 6, pp. 1095-1107, 2003.

[31] F. J. Kaye, P. A. J. Bunn, S. M. Stinberg et al., "A randomized trial comparing combination electro beam radiation and chemotherapy with topical therapy in the initial treatment of mycosis fungoides," The New England Journal of Medicine, vol. 321, no. 26, pp. 1748-1790, 1989.

[32] H. S. Zackheim, M. Kashani-Sabet, and S. Amin, "Topical corticosteroids for mycosis fungoides: experience in 79 patients," Archives of Dermatology, vol. 134, no. 8, pp. 949-954, 1998.

[33] H. S. Zackheim, M. Kashani-Sabet, and S. Amin, "Topical corticosteroids for mycosis fungoides: experience in 79 patients," Archives of Dermatology, vol. 134, no. 8, pp. 949-954, 1998.

[34] D. Breneman, M. Duvic, T. Kuzel, R. Yocum, J. Truglia, and V. J. Stevens, "Phase 1 and 2 trial of bexarotene gel for skin-directed treatment of patients with cutaneous T-cell lymphoma," Archives of Dermatology, vol. 138, no. 3, pp. 325332, 2002.

[35] C. J. Karzmark, “Total skin electron therapy: technique and dosimetry," American Association of Physicists in Medicine Report 23, 1987.

[36] J. E. Bolden, M. J. Peart, and R. W. Johnstone, "Anticancer activities of histone deacetylase inhibitors," Nature Reviews Drug Discovery, vol. 5, no. 9, pp. 769-784, 2006.

[37] P. A. Marks, R. A. Rifkind, V. M. Richon, R. Breslow, T. Miller, and W. K. Kelly, "Histone deacetylases and cancer: causes and therapies," Nature Reviews Cancer, vol. 1, no. 3, pp. 194-202, 2001.

[38] M. Dokmanovic, C. Clarke, and P. A. Marks, "Histone deacetylase inhibitors: overview and perspectives," Molecular Cancer Research, vol. 5, no. 10, pp. 981-989, 2007.

[39] P. A. Marks, "Histone deacetylase inhibitors: a chemical genetics approach to understanding cellular functions," Biochimica et Biophysica Acta, vol. 1799, no. 10-12, pp. 717-725, 2010.

[40] S. Minucci and P. G. Pelicci, "Histone deacetylase inhibitors and the promise of epigenetic (and more) treatments for cancer," Nature Reviews Cancer, vol. 6, no. 1, pp. 38-51, 2006.

[41] A. Tumber, L. S. Collins, K. D. Petersen et al., "The histone deacetylase inhibitor PXD101 synergises with 5-fluorouracil to inhibit colon cancer cell growth in vitro and in vivo," Cancer Chemotherapy and Pharmacology, vol. 60, no. 2, pp. 275-283, 2007.

[42] J. Tan, S. Cang, Y. Ma, R. L. Petrillo, and D. Liu, "Novel histone deacetylase inhibitors in clinical trials as anti-cancer agents," Journal of Hematology and Oncology, vol. 3, article 5, 2010.

[43] H. Akazawa and I. Komuro, "Roles of cardiac transcription factors in cardiac hypertrophy," Circulation Research, vol. 92, no. 10, pp. 1079-1088, 2003.

[44] T. Kouzarides, "Chromatin modifications and their function," Cell, vol. 128, no. 4, pp. 693-705, 2007.

[45] S. Thiagalingam, K. H. Cheng, H. J. Lee, N. Mineva, A. Thiagalingam, and J. F. Ponte, "Histone deacetylases: unique players in shaping the epigenetic histone code," Annals of the New York Academy of Sciences, vol. 983, pp. 84-100, 2003.

[46] C. L. Peterson and M. A. Laniel, "Histones and histone modifications," Current Biology, vol. 14, no. 14, pp. R546-551, 2004.

[47] P. A. Marks, V. M. Richon, and R. A. Rifkind, "Histone deacetylase inhibitors: inducers of differentiation or apoptosis of transformed cells," Journal of the National Cancer Institute, vol. 92, no. 15, pp. 1210-1216, 2000.

[48] S. Cang, Y. Ma, and D. Liu, "New clinical developments in histone deacetylase inhibitors for epigenetic therapy of cancer," Journal of Hematology and Oncology, vol. 2, article 22, 2009.

[49] S. Y. Roth, J. M. Denu, and C. D. Allis, "Histone acetyltransferases," Annual Review of Biochemistry, vol. 70, pp. 81-120, 2001.

[50] B. C. Smith and J. M. Denu, "Chemical mechanisms of histone lysine and arginine modifications," Biochimica et Biophysica Acta, vol. 1789, no. 1, pp. 45-57, 2009.

[51] M. H. Kuo, "Roles of histone acetyltransferases and deacetylases in gene regulation," BioEssays, vol. 20, no. 8, pp. 615-626, 1998.

[52] J. C. Kim, E. S. Shin, C. W. Kim et al., "In vitro evaluation of histone deacetylase inhibitors as combination agents for colorectal cancer," Anticancer Research, vol. 29, no. 8, pp. 3027-3034, 2009. 
[53] S. G. Gray and T. J. Ekström, "The human histone deacetylase family," Experimental Cell Research, vol. 262, no. 2, pp. 75-83, 2001.

[54] P. A. Marks, V. M. Richon, and R. A. Rifkind, "Histone deacetylase inhibitors: inducers of differentiation or apoptosis of transformed cells," Journal of the National Cancer Institute, vol. 92, no. 15, pp. 1210-1216, 2000.

[55] A. J. M. De Ruijter, A. H. Van Gennip, H. N. Caron, S. Kemp, and A. B. P. Van Kuilenburg, "Histone deacetylases (HDACs): characterization of the classical HDAC family," Biochemical Journal, vol. 370, no. 3, pp. 737-749, 2003.

[56] X. J. Yang and E. Seto, "Collaborative spirit of histone deacetylases in regulating chromatin structure and gene expression," Current Opinion in Genetics and Development, vol. 13, no. 2, pp. 143-153, 2003.

[57] T. A. Miller, D. J. Witter, and S. Belvedere, "Histone deacetylase inhibitors," Journal of Medicinal Chemistry, vol. 46, no. 24, pp. 5097-5116, 2003.

[58] S. Cang, Y. Ma, and D. Liu, "New clinical developments in histone deacetylase inhibitors for epigenetic therapy of cancer," Journal of Hematology and Oncology, vol. 2, article 22, 2009.

[59] D. Siegel, M. Hussein, C. Belani et al., "Vorinostat in solid and hematologic malignancies," Journal of Hematology and Oncology, vol. 2, article 31, 2009.

[60] L. Ellis, P. W. Atadja, and R. W. Johnstone, "Epigenetics in cancer: targeting chromatin modifications," Molecular Cancer Therapeutics, vol. 8, no. 6, pp. 1409-1420, 2009.

[61] H. M. Prince, M. J. Bishton, and R. W. Johnstone, "Panobinostat (LBH589): a potent pan-deacetylase inhibitor with promising activity against hematologic and solid tumors," Future Oncology, vol. 5, no. 5, pp. 601-612, 2009.

[62] B. S. Mann, J. R. Johnson, M. H. Cohen, R. Justice, and R. Pazdur, "FDA approval summary: vorinostat for treatment of advanced primary cutaneous T-cell lymphoma," Oncologist, vol. 12, no. 10, pp. 1247-1252, 2007.

[63] E. A. Olsen, Y. H. Kim, T. M. Kuzel et al., "Phase IIB multicenter trial of vorinostat in patients with persistent, progressive, or treatment refractory cutaneous T-cell lymphoma," Journal of Clinical Oncology, vol. 25, no. 21, pp. 3109-3115, 2007.

[64] M. Crump, B. Coiffier, E. D. Jacobsen et al., "Phase II trial of oral vorinostat (suberoylanilide hydroxamic acid) in relapsed diffuse large-B-cell lymphoma," Annals of Oncology, vol. 19, no. 5, pp. 964-969, 2008.

[65] W. K. Kelly, O. A. O'Connor, L. M. Krug et al., "Phase I study of an oral histone deacetylase inhibitor, suberoylanilide hydroxamic acid, in patients with advanced cancer," Journal of Clinical Oncology, vol. 23, no. 17, pp. 3923-3931, 2005.

[66] A. Sabharwal and D. Kerr, "Chemotherapy for colorectal cancer in the metastatic and adjuvant setting: past, present and future," Expert Review of Anticancer Therapy, vol. 7, no. 4, pp. 477-487, 2007.

[67] K. B. Hymes, "The role of histone deacetylase inhibitors in the treatment of patients with cutaneous T-Cell lymphoma," Clinical Lymphoma, Myeloma and Leukemia, vol. 10, no. 2, pp. 98-109, 2010.

[68] C. Mercurio, S. Minucci, and P. G. Pelicci, "Histone deacetylases and epigenetic therapies of hematological malignancies," Pharmacological Research, vol. 62, no. 1, pp. 18-34, 2010.

[69] R. L. Piekarz, R. Frye, M. Turner et al., "Phase II multi-institutional trial of the histone deacetylase inhibitor romidepsin as monotherapy for patients with cutaneous Tcell lymphoma," Journal of Clinical Oncology, vol. 27, no. 32, pp. 5410-5417, 2009.
[70] M. Dickinson, R. W. Johnstone, and H. M. Prince, "Histone deacetylase inhibitors: potential targets responsible for their anti-cancer effect," Investigational New Drugs, vol. 28, no. 1, pp. S3-S20, 2010.

[71] V. Sandor, S. Bakke, R. W. Robey et al., "Phase I trial of the histone deacetylase inhibitor, depsipeptide (FR901228, NSC 630176), in patients with refractory neoplasms," Clinical Cancer Research, vol. 8, no. 3, pp. 718-728, 2002.

[72] A. Saito, T. Yamashita, Y. Mariko et al., "A synthetic inhibitor of histone deacetylase, MS-27-275, with marked in vivo antitumor activity against human tumors," Proceedings of the National Academy of Sciences of the United States of America, vol. 96, no. 8, pp. 4592-4597, 1999.

[73] A. Jona, N. Khaskhely, D. Buglio et al., "The histone deacetylase inhibitor entinostat (SNDX-275) induces apoptosis in Hodgkin lymphoma cells and synergizes with Bcl-2 family inhibitors," Experimental Hematology, vol. 39, no. 10, pp. 1007.e1-1017.e1, 2011.

[74] K. R. Suchin, M. Cassin, S. L. Gottleib et al., "Increased interleukin 5 production in eosinophilic Sézary syndrome: regulation by interferon alfa and interleukin 12," Journal of the American Academy of Dermatology, vol. 44, no. 1, pp. 28-32, 2001.

[75] B. R. Vowels, M. Cassin, E. C. Vonderheid, and A. H. Rook, "Aberrant cytokine production by Sezary syndrome patients: cytokine secretion pattern resembles murine Th2 cells," Journal of Investigative Dermatology, vol. 99, no. 1, pp. 90-94, 1992.

[76] B. R. Vowels, S. R. Lessin, M. Cassin et al., "Th2 cytokine mRNA expression in skin in cutaneous T-cell lymphoma," Journal of Investigative Dermatology, vol. 103, no. 5, pp. 669673, 1994.

[77] K. Asadullah, W. D. Döcke, A. Haeuler, W. Sterry, and H. D. Volk, "Progression of mycosis fungoides is associated with increasing cutaneous expression of interleukin-10 mRNA," Journal of Investigative Dermatology, vol. 107, no. 6, pp. 833837, 1996.

[78] P. Gimsing, "Belinostat: a new broad acting antineoplastic histone deacetylase inhibitor," Expert Opinion on Investigational Drugs, vol. 18, no. 4, pp. 501-508, 2009.

[79] X. Qian, G. Ara, E. Mills, W. J. LaRochelle, H. S. Lichenstein, and M. Jeffers, "Activity of the histone deacetylase inhibitor belinostat (PXD101) in preclinical models of prostate cancer," International Journal of Cancer, vol. 122, no. 6, pp. 1400-1410, 2008.

[80] P. Gimsing, M. Hansen, L. M. Knudsen et al., "A phase I clinical trial of the histone deacetylase inhibitor belinostat in patients with advanced hematological neoplasia," European Journal of Haematology, vol. 81, no. 3, pp. 170-176, 2008.

[81] N. L. Steele, J. A. Plumb, L. Vidal et al., "A phase 1 pharmacokinetic and pharmacodynamic study of the histone deacetylase inhibitor belinostat in patients with advanced solid tumors," Clinical Cancer Research, vol. 14, no. 3, pp. 804-810, 2008.

[82] S. S. Ramalingam, C. P. Belani, C. Ruel et al., "Phase II study of belinostat (PXD101), a histone deacetylase inhibitor, for second line therapy of advanced malignant pleural mesothelioma," Journal of Thoracic Oncology, vol. 4, no. 1, pp. 97-101, 2009.

[83] W. Shao, J. D. Growney, Y. Feng et al., "Potent anticancer activity of the pan-deacetylase inhibitor panobinostat (LBH589) as a single agent in in vitro and in vivo tumor models," Proceedings of the 99th American Association of Cancer Research Annual Meeting, April 2008. 
[84] P. Atadja, "Development of the pan-DAC inhibitor panobinostat (LBH589): successes and challenges," Cancer Letters, vol. 280, no. 2, pp. 233-241, 2009.

[85] M. Duvic, J. C. Becker, and S. Dalle, "Phase II trial of oral panobinostat (LBH589) in patients with refractory cutaneous T-cell lymphoma (CTCL)," in Proceedings of the ASH Annual Meeting Abstracts, vol. 112, p. 1005, 2008.

[86] C. Zhang, V. Richon, X. Ni, R. Talpur, and M. Duvic, "Selective induction of apoptosis by histone deacetylase inhibitor SAHA in cutaneous T-cell lymphoma cells: relevance to mechanism of therapeutic action," Journal of Investigative Dermatology, vol. 125, no. 5, pp. 1045-1052, 2005. 


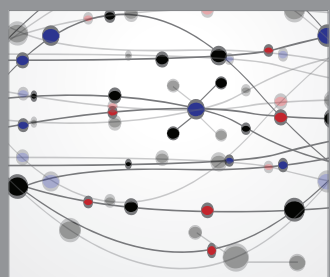

The Scientific World Journal
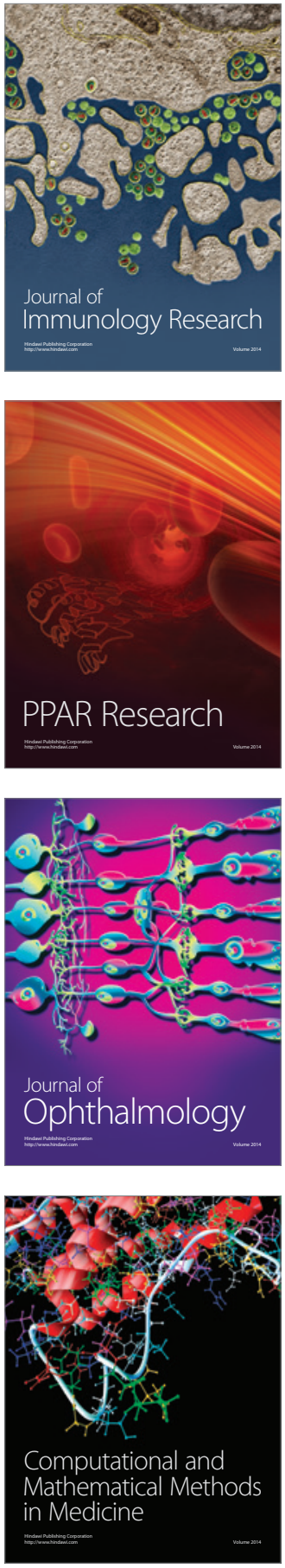

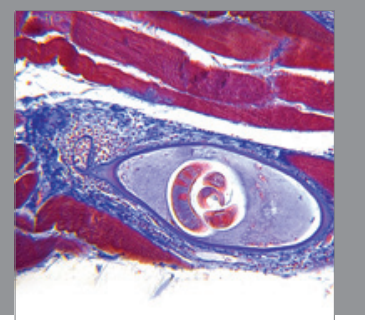

Gastroenterology

Research and Practice
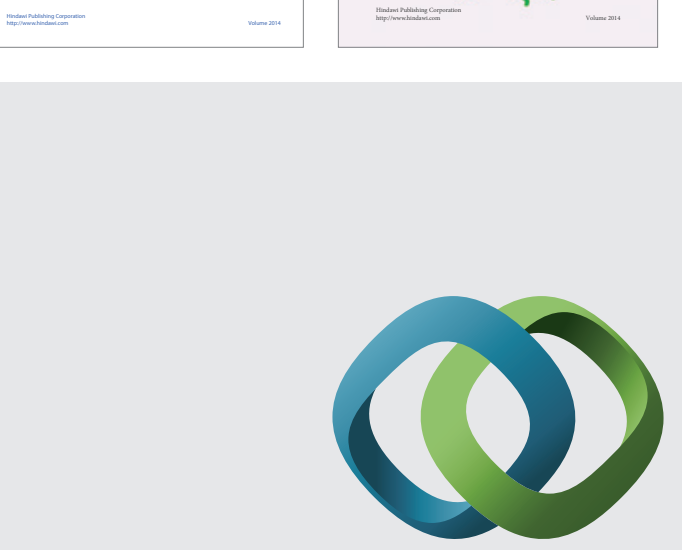

\section{Hindawi}

Submit your manuscripts at

http://www.hindawi.com
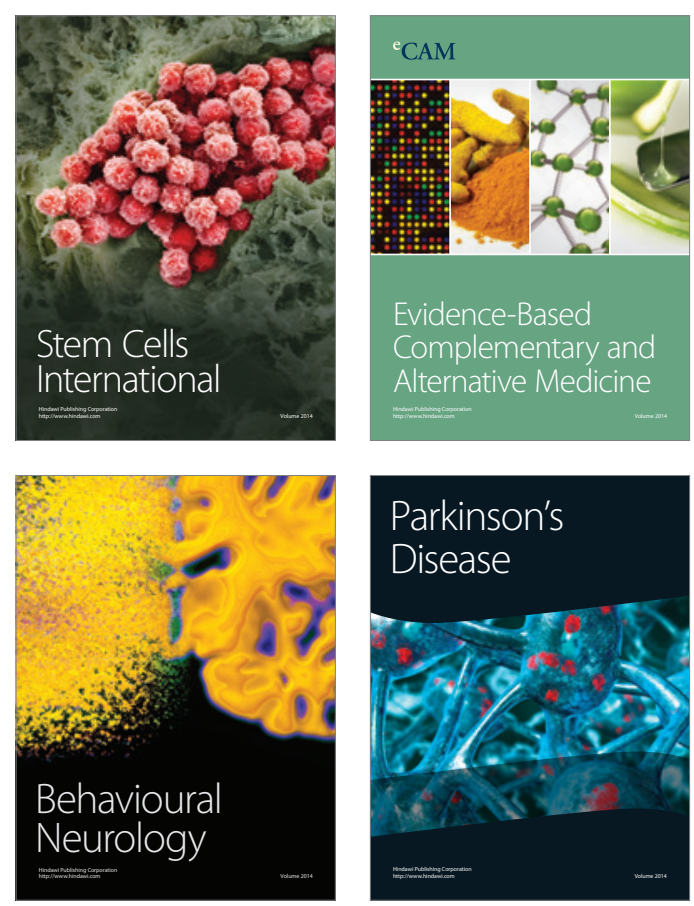

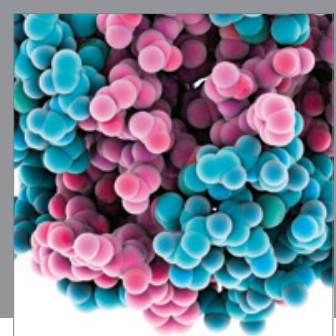

Journal of
Diabetes Research

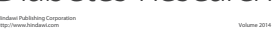

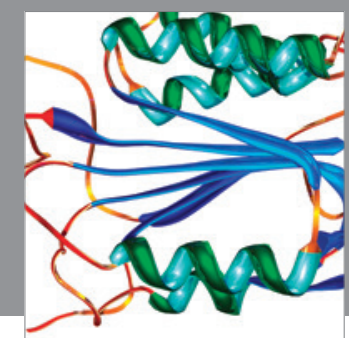

Disease Markers
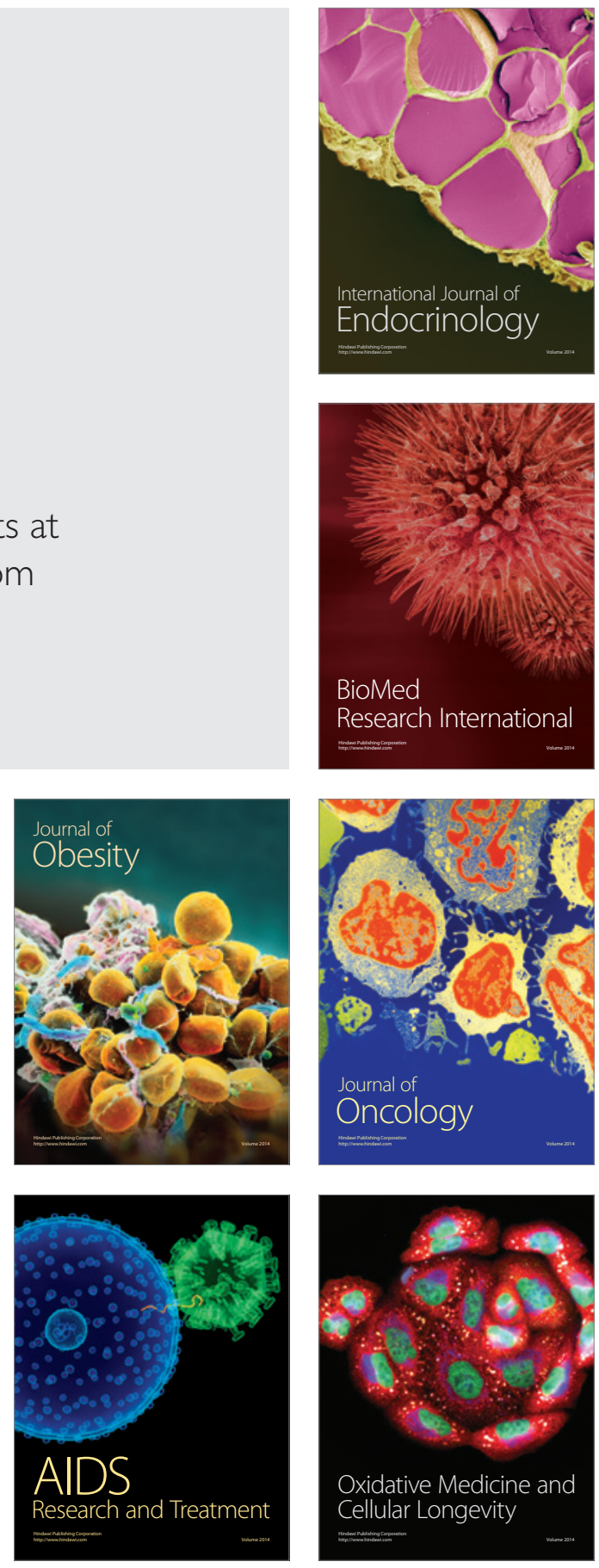